\title{
GEOARQUEOLOGÍA LATINOAMERICANA
}

\author{
Ana Cecilia Mauricio Llonto
}

Teóricamente, la geoarqueología es una rama de la arqueología que aplica conceptos y métodos de las ciencias de la tierra (geología, geografía, geomorfología, sedimentología, estratigrafía, geocronología, pedología, entre otros), para la solución de problemas y preguntas arqueológicas, principalmente aquellas que tienen que ver con la formación del registro arqueológico (Waters 1992; Rapp y Hill 2006). Aunque el uso más extendido de la práctica geoarqueológica se haya dado recién a partir de la década de 1970, las ciencias de la tierra y la arqueología han estado íntimamente ligados desde los inicios de la disciplina. Basta recordar que algunos de los principios básicos de la arqueología, como la superposición y la recurrencia, fueron tomados de las geociencias, así como la importancia del estudio de la estratigrafía y de la cronología relativa y absoluta del registro arqueológico. Esta temprana colaboración entre las ciencias de la tierra y la arqueología dio paso, con el tiempo, a una nueva rama de especialización arqueológica, la geoarqueología, que se desarrollaría con mayor intensidad a partir de la influencia de la arqueología procesual y su llamado a incorporar información de las ciencias naturales en la investigación arqueológica (Binford 1983).

El desarrollo y la aplicación de la geoarqueología lleva ya varias décadas tanto en Europa como en los Estados Unidos. En América Latina y particularmente en América del Sur, las investigaciones geoarqueológicas empiezan a darse con mayor frecuencia a partir de la segunda mitad de la década de 1980. Desde entonces los estudios geoarqueológicos han cubierto una gran variedad de temas y regiones que van desde los clásicos temas de formación del registro arqueológico hasta temas medioambientales y paleoclimáticos (v.g., Rollins et al. 1986; Sandweiss 1986; Zárate y Flegenheimer 1991). No es la intención de esta nota introductoria presentar una revisión histórica de la práctica geoarqueológica en la región, por el contrario, buscamos presentar parte del contexto contemporáneo. En las últimas tres décadas y particularmente a partir del siglo XXI, las investigaciones geoarqueológicas no solo han ido en aumento en Latinoamérica, sino que también ha aumentado su práctica por investigadores de la misma región. Así, por ejemplo, no solo han aumentado los proyectos y publicaciones geoarqueológicas encabezados por investigadores latinoamericanos, sino también los simposios, congresos y cursos dedicados al tema. Una muestra de esto es la edición especial de la revista Geoarchaeology, publicada en el año 2017: Environmental dynamics and formation processes of the archaeological record in Latin America (Favier y Rubin 2017). Por otro lado, la agrupación de profesionales en torno a la geoarqueología se observa con el Grupo de Estudios Geoarqueológicos de América Latina (GEGAL), formado en el año 2012, el cual organiza reuniones anuales en diversos países de Centro y Sudamérica. La práctica de la geoarqueología en Latinoamérica ha llevado también al establecimiento de cursos en las currículas universitarias de pre y posgrado, grupos de investigación interdisciplinarios y la formación de laboratorios en diversas universidades de la región. Es precisamente dentro de este espíritu de difusión y crecimiento de las investigaciones interdisciplinarias, que surge la idea de esta publicación, dedicada a presentar diversos trabajos geoarqueológicos de Latinoamérica.

a https://orcid.org/0000-0002-7293-6233. Pontificia Universidad Católica del Perú, Sección de Arqueología. cecilia. mauricio@pucp.edu.pe 
Los artículos que se presentan en este y el siguiente número del Boletín de Arqueología PUCP fueron parte de las presentaciones del simposio titulado Encuentro Latinoamericano de Goearqueología, organizado por la editora de estos números, en colaboración con el GEGAL, siendo el primer simposio de geoarqueología que se organizaba en Perú. Este evento se realizó en el auditorio del Departamento de Humanidades de la Pontificia Universidad Católica del Perú, entre el 25 y 27 de setiembre de 2019 y contó con la participación de expositores de Argentina, Colombia, Chile, Costa Rica, Ecuador, Estados Unidos, México, Perú y Uruguay. Las ponencias fueron agrupadas en mesas que discutían cuatro temas. Retomando dos temas clásicos de la práctica geoarqueológica, se incluyó el tema formación de sitio y cronología; el cual abarcó el grupo más grande de presentaciones. Para prestar atención a las nuevas tendencias y tecnologías se incluyeron las mesas temáticas de análisis espacial y exploración remota, análisis de materiales y reconstrucciones paleoclimáticas/paleoambientales.

Este primer número presenta artículos que se agrupan en dos ejes temáticos: formación de sitios y cronología, y análisis de materiales. En el primer eje se incluyen cinco artículos de Ecuador, Brasil, Argentina y Uruguay. En primer lugar, el artículo de Gabriela López y Sthefano Serrano, analiza la formación y distribución de montículos artificiales (o tolas) de los grupos culturales karankikayampi, en el complejo volcánico Imbabura (provincia de Imbabura, sierra norte de Ecuador). A través de análisis estratigráfico y excavaciones restringidas, los autores demuestran la existencia de depósitos culturales en diferentes montículos que conforman el paisaje de este complejo, muchas de estas ocupaciones no habían sido reconocidas previamente. Estas ocupaciones y transformaciones del paisaje evidencian tanto el uso de montículos naturales formados por depósitos de naturaleza volcánica, como la formación artificial de montículos durante el Período de Integración Tardío, e incluso en períodos más tempranos. Por su parte, Barbosa, Afonso y Rubin, presentan un estudio micromorfológico y geoquímico de dos sitios asociados a alfareros de la tradición uru, en la cuenca del río Araguaia, Goiás, Brasil. Estos análisis geoquímicos y micromorfológicos permitieron identificar el origen antrópico de los sedimentos que componen los sitios Cangas I y Lago Rico, a través de la presencia de contextos como fogones, viviendas o áreas de descarte; así como fragmentos de huesos, carbón y otros desechos microscópicos. Asimismo, los autores sugieren un origen antrópico para los suelos oscurecidos. Seguidamente, Favier Dubois y colaboradores, presentan una propuesta de estudio los procesos y patrones de desarrollo de la estratigrafía y morfología de cuevas someras y aleros, basados en diferentes contextos geológicos del norte, centro y sur de la Argentina. Usando una perspectiva comparativa inter e intrarregional, los autores plantean que la identificación de patrones de formación y transformación, puede usarse como una herramienta para la interpretación arqueológica y tafonómica (v.g. conservación, cronología, etc.) de este tipo de contextos. Por otro lado, Herrera y Steffan combinan análisis sedimentológicos y esclerocronología de valvas marinas para abordar el estudio de los procesos de formación de conchales arqueológicos ubicados en la costa norte del golfo de San Matías (Río Negro, Argentina). Este trabajo combina, además, información climatológica para analizar la influencia de estos factores en los procesos sedimentarios y de geomorfología costeros, que determinan la preservación de los contextos arqueológicos asociados a la formación de conchales. Este primer eje temático concluye con la investigación de Bortolotto y colaboradores, quienes analizan posibles modificaciones antropogénicas del entorno físico y biológico en el sitio arqueológico de Isla Vizcaíno 1, en el delta del Río Negro, Uruguay. A través del análisis de suelos que combinan análisis granulométricos, composicionales y geoquímicos, los autores demuestran el rol de la acción humana, relacionada a actividades domésticas de pequeña escala, en la formación de suelos y la modificación del paisaje.

El segundo eje temático que se presenta en este número, análisis de materiales, incluye trabajos de Ecuador y Perú. En primer lugar, Serrano analiza el intercambio a larga distancia entre los Andes y la Amazonía baja del Ecuador sobre la base de la presencia de obsidiana. A través de análisis de artefactos líticos, fluorescencia de rayos X, análisis de perfiles estratigráficos, el uso 
de sistemas de información geográfica y datos palinológicos, Serrano propone que la obsidiana reportada sitios arqueológicos de la Amazonía baja ecuatoriana corresponde al uso de depósitos secundarios fluviales que datan del Pleistoceno, mucho antes del arribo de grupos humanos a esta región. Por su parte, González-Gómez de Agüero y colegas analizan un pigmento representativo del estilo cerámico que caracteriza al sitio Cerro de Oro, ubicado en la costa sur de Perú para hablar la cadena operativa de producción de cerámica del estilo local denominado por los autores como Cerro de Oro. Este trabajo analiza y compara cerámica del sitio con muestras minerales locales usando fluorescencia de rayos X, microscopía Raman y difracción de rayos X; llegando a identificar la explotación de un pigmento de origen local (epidota) para la producción de cerámica en el sitio y posiblemente, en asentamientos vecinos, durante el Horizonte Medio.

El simposio que dio origen a estos dos números fue posible gracias al apoyo y colaboración de diferentes unidades de la Pontificia Universidad Católica del Perú, en primer lugar, el Departamento de Humanidades y la Sección de Arqueología, la Dirección de Gestión de la Investigación (DGI) y la Dirección de Actividades Culturales (DACU). Asimismo, quisiera agradecer la colaboración de Cristian Favier Dubois y el GEGAL, ya que este simposio se dio dentro del marco de las reuniones anuales que realiza el GEGAL. Gracias al apoyo de la empresa Cálidda y el Museo Larco se logró la implementación del programa. Finalmente, agradezco la colaboración voluntaria de los estudiantes de arqueología de la Pontificia Universidad Católica del Perú y la Universidad Nacional Mayor de San Marcos durante el desarrollo del evento.

\section{Referencias}

Binford, L. (1983). In pursuit of the past: Decoding the archaeological record. Thames and Hudson. New York.

Favier Dubois, C. y J. Rubin de Rubin (2017). Environmental dynamics and formation processes of the archaeological record in Latin America. Geoarchaeology 32(6), 603-604. https://doi.org/10.1002/gea.21657

Rapp, G. y C. Hill (2006). Geoarchaeology: The earth-science approach to archaeological interpretation. 2da edición. Yale University Press. New Haven/Londres.

Rollins, H.B., J.B. Richardson III y D.H. Sandweiss (1986). The Birth of El Niño: Geoarchaeological Evidence and Implications. Geoarchaeology 1, 3-15.

Sandweiss, D.H. (1986). The Beach Ridges at Santa, Peru: El Niño, Uplift, and Prehistory. Geoarchaeology 1, 17-28.

Waters, M. (1992). Principles of geoarchaeology: A North American perspective. University of Arizona Press. Tucson.

Zárate, M.A. y N. Flegenheimer (1991). Geoarchaeology of the Cerro la China locality (Buenos Aires, Argentina): Site 2 and site 3. Geoarchaeology 6(3), 273-294. 